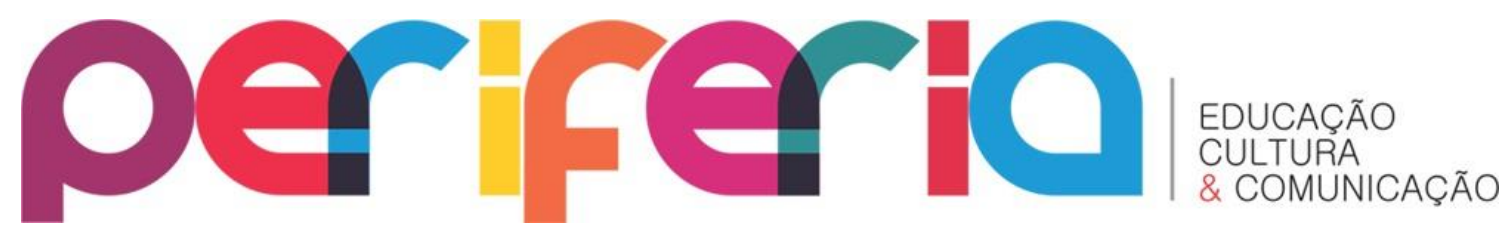

ISSN:1984-9540

DOI: $10.12957 /$ periferia. 2020.55170

\title{
NARRATIVAS E SEUS ENCANTAMENTOS: ENTRE ZUELAS E AXÓS DE TATA LONDIRÁ
}

\author{
Jackeline Rodrigues Mendes ${ }^{1}$ \\ Marta Ferreira ${ }^{2}$
}

\section{Resumo}

Neste texto pretendemos abordar a construção de narrativas em uma perspectiva decolonial a partir de Tata Londirá, pai de santo conhecido como Joãozinho da Goméia, que tem um papel singular na visibilidade do candomblé do século XX. A noção de narrativa e suas relações com o encantamento em práticas afrodiásporicas pretende ser discutida pelo deslocamento da dicotomia colonial posta entre sociedades orais e sociedades letradas, entre oral-escrito que colocou uma centralidade da noção de escrita apenas atrelada ao verbal. Tal divisão relegou tais práticas apenas ao âmbito da oralidade como forma de oposição e ausência de escrita. Pretendemos, a partir das zuelas (cantos) e axós (vestimentas do candomblé) de Tata Londirá, discutir os modos de produção das narrativas no candomblé de Joãozinho da Goméia e as relações que podem ser estabelecidas entre encantamento e a produção de outros modos de escrita. Além disso, discutimos a força de narrador de Tata Londirá ao transpor para fora dos muros dos terreiros tais narrativas em toda sua estética, visualidade e encantamento.

Palavras-chave: Educação nos Terreiros; Narrativas Afrodiaspóricas; Filosofias do Encantamento

\section{NARRATIVES AND THEIR ENCHANTMENTS: BETWEEN TATA LONDIRÁ'S ZUELAS AND AXÓS}

\section{Abstract}

This text intends to approach narratives construction in a decolonial perspective, walking the paths traced by Tata Londirá, pai de santo known as Joãozinho da Goméia, who has a unique role in the visibility of candomble in 20th century. The notion of narrative and its relationship with enchantment in aphrodisporic practices intends to be discussed by the displacement of

\footnotetext{
${ }^{1}$ Docente na Faculdade de Educação no Depto de Ensino e Práticas Culturais da Universidade Estadual de Campinas (UNICAMP). http://orcid.org/0000-0001-8607-4761. E-mail: jamendes@unicamp.br

${ }^{2}$ Doutoranda Faculdade de Educação linha Linguagem, educação e Arte da Universidade Estadual de Campinas (UNICAMP). ORCID iD: https://orcid.org/0000-0002-5613-5815. E-mail:

14martaferreira@gmail.com
}

Periferia, v. 12, n. 3, p. 39-52, set./dez. 2020 


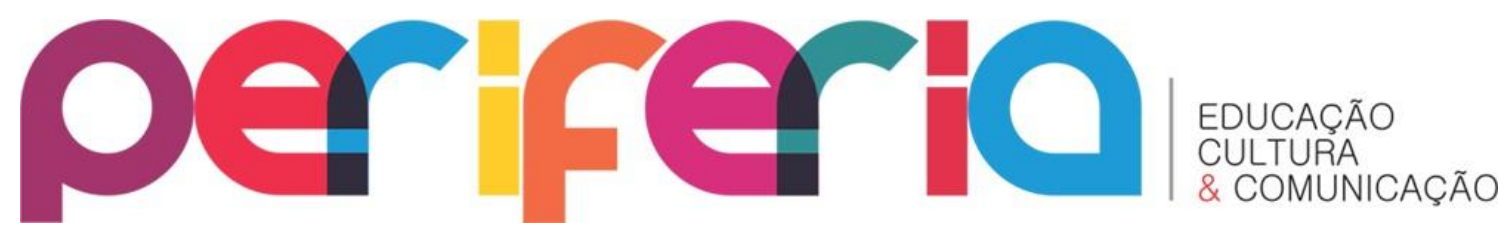

ISSN:1984-9540

DOI: $10.12957 /$ periferia.2020.55170

colonial dichotomy between oral and literate societies, between oral-writing that placed a centrality to writing just linked to verbal form. Such division relegated these practices only to the sphere of orality as a form of opposition and absence of writing. We intend, from the zuelas (chants) and axós (candomblé garments) by Tata Londirá, to discuss the modes of production of narratives in Joãozinho da Goméia's candomblé and the relationships that can be established between enchantment and the production of other modes of writing. In addition, we discussed the strength of Tata Londirá as a narrator when transposing such narratives outside the walls of candomble communities in all their aesthetics, visuality and enchantment.

Key words: Education in terreiros; aphrodisporic narratives; philosophies of enchantment

\section{NARRATIVAS E SUS ENCANTAMIENTOS: ENTRE ZUELAS Y AXÓS DE TATA LONDIRÁ}

\section{Resumen}

En el presente texto pretendemos abordar la construcción de narrativas en una perspectiva decolonial desde Tata Londirá, pai de santo conocido como Joãozinho da Goméia, que tuvo un papel único en la visibilidad del candomblé del siglo XX. La noción de narrativa y su relación con el encantamiento en las prácticas afrodiasporicas pretende ser discutida a través del desplazamiento de la dicotomía colonial entre sociedades orales y sociedades alfabetizadas, entre escritura y oralidad, que establecia una noción de escritura ligada únicamente a lo verbal. Tal división relegó tales prácticas únicamente al ámbito de la oralidad como forma de oposición y ausencia de escritura. Pretendemos, a partir de las zuelas (cánticos) y axós (prendas de candomblé) de Tata Londirá, discutir los modos de producción de narrativas en el candomblé de Joãozinho da Goméia y las relaciones que se pueden establecer entre el encantamiento y la producción de otros modos de escritura. Además, comentamos la fuerza del narrador de Tata Londirá al trasponer tales narrativas fuera de los muros del terreiro en toda su estética, visualidad y encanto.

Palabras clave: Educación en los Terreiros; Narrativas Afrodiaspóricas;

Filosofías del encantamiento

Periferia, v. 12, n. 3, p. 39-52, set./dez. 2020 


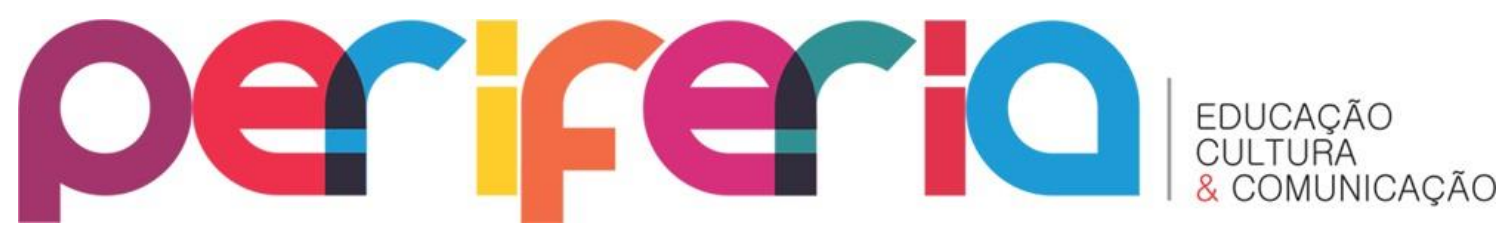

O narrador Tata Londirá

“Vou-me embora p'ro sertão

Viola meu bem, viola!

Que eu aqui não me dou bem

Viola meu bem, viola

Sou empregado da Leste, sou maquinista do trem

Vou-me embora p'ro sertão

Que eu aqui não me dou bem

Oh viola meu bem, viola..."3

Azuelada 4 /cantada por Joãozinho da Goméia no álbum "O Rei do Candomblé", a toada acima, por um lado, pode representar o oposto do que ele viveu e defendeu em sua trajetória - lutou contra a invisibilidade e perseguições aos candomblés, utilizando suas narrativas diversas, narrativas essas que contradiziam os discursos coloniais de seu tempo. Por outro lado, também apresenta o vínculo forte que se mantêm com as raízes e a ancestralidade na cantiga do encantado. Não voltou para o sertão, mas criou seu espaçotempo de tradição afrodiaspórica, acolhendo, cuidando, publicizando práticas até então criminalizadas pelo cunho colonial. Foi um homem do seu tempo, mas com práticas decoloniais.

Abriu as portas do terreiro para políticos, gravou discos com cantigas de tipos variados de candomblés, escritor de coluna em jornal, citado em jornais e revistas, para além dos informes policiais tão comuns à época.

É nesse caminho que esse ensaio se propõe a dialogar com algumas narrativas de Joãozinho da Goméia, especificamente observando algumas zuelas/cantos e axós/vestimentas que compunham seus discursos de

\footnotetext{
${ }^{3}$ Toada para caboclo do álbum “O rei do candomblé" de Joãozinho da Goméia

${ }^{4} \mathrm{O}$ verbo kuzuela (infinitivo) na língua kimbundu tem um significado amplo que indica sentidos em torno de falar, conversar, dizer ou soar (JÚNIOR, sd). Ele tem sido usado de diferentes formas no português bantu, como por exemplo: azuelar, zuelar, ele zuelou, zuelas, entre outras.
} 


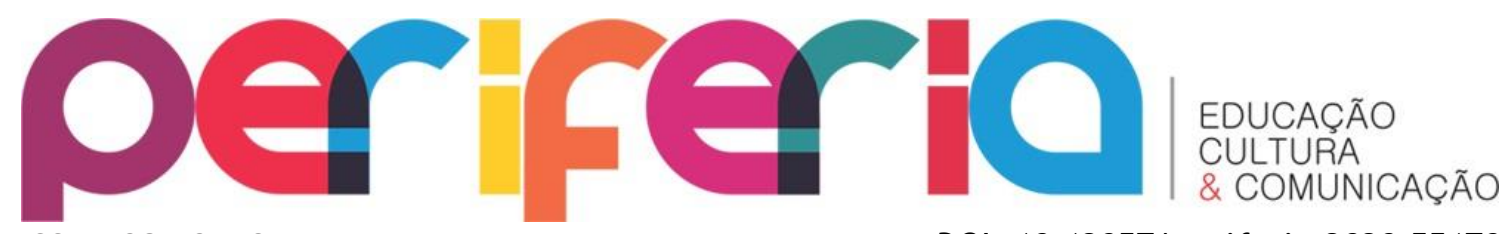

ISSN:1984-9540

DOI: $10.12957 /$ periferia. 2020.55170 divulgação dos candomblés; refletindo, também, sobre como Joãozinho da Goméia, com narrativas diversas, SULeou (CAMPOS, 2010) as narrativas coloniais a partir de suas vivências com as práticas do candomblé e as culturas afrodiaspóricas.

Tata Londirá - azuelando para além das colunas policiais

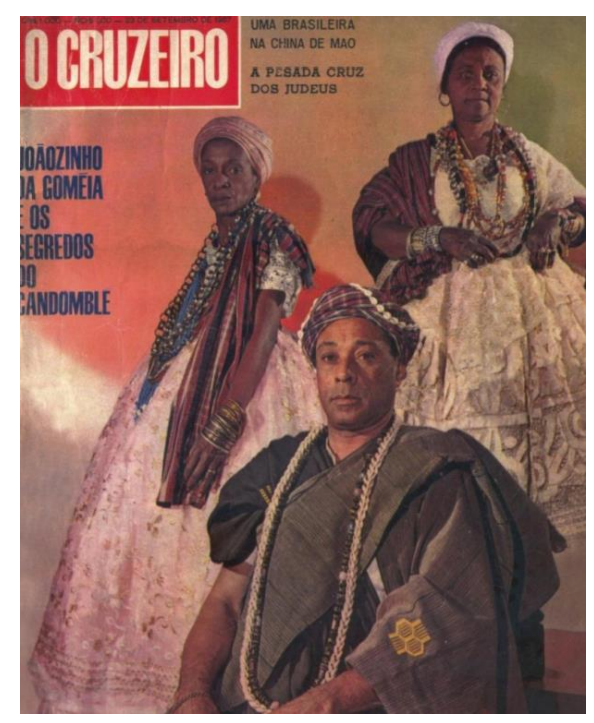

Fonte: Mendes (2012, p.109)

Em setembro do 1967, uma capa de revista de grande circulação nacional, $O$ Cruzeiro, estampa uma imagem não muito comum em edições anteriores ${ }^{5}$, o texto no comentário sobre a capa também reconhece que "o mais famoso babalorixá brasileiro faz capa diferente e cria assunto de interesse antropológico". Enquanto texto jornalístico, o título de chamada na capa para a matéria, "Joãozinho da Goméia e os segredos do candomblé", ensaia uma apresentação que propõe trazer uma narrativa sobre o candomblé, a partir da ideia de uma prática religiosa misteriosa, pelo título que encabeça

\footnotetext{
${ }^{5}$ Mendes (2014), em seu livro intitulado "Vestidos de realeza: fios e nós centro-africanos no candomblé de Joãozinho da Goméia", ao discutir a matéria produzida sobre essa edição da Revista Cruzeiro, ressalta esse aspecto de ser uma capa incomum em relação a de números anteriores, os quais, em geral, colocavam fotos de mulheres sem vínculo direto com alguma matéria da revista.
}

Periferia, v. 12, n. 3, p. 39-52, set./dez. 2020 


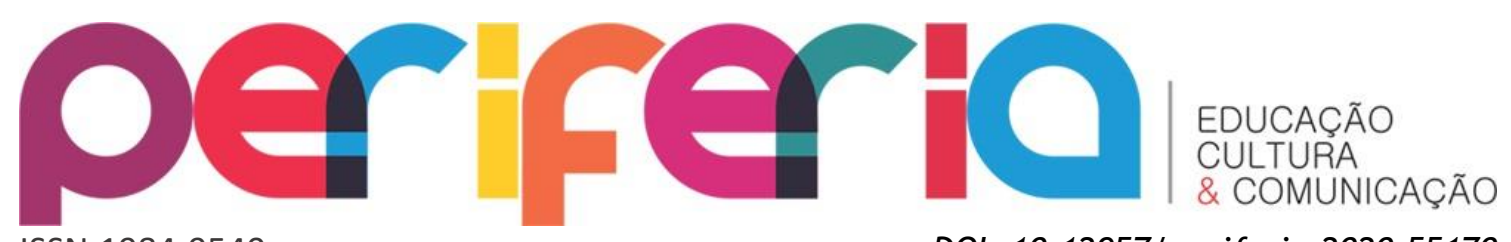

ISSN:1984-9540

DOI: $10.12957 /$ periferia.2020.55170 a reportagem "Ronda misteriosa dos Orixás", mas que também se tornou um lugar de interesse para a construção de narrativas antropológicas, ao indicar a contribuição da leitura de autores como Nina Rodrigues, Edson Carneiro, Artur Ramos e Roger Bastide. No início da matéria, embora o texto da reportagem mencione a participação de Joãozinho da Goméia com informações importantes para a composição do texto escrito, não há indicação onde estão as informações efetivamente dadas por ele. Assim, nesse cenário que pretende trazer uma objetificação de uma prática afrodiaspórica apelando para o mistério e o exótico, à moda da construção de narrativas coloniais sobre o outro, o que queremos destacar é o caminho decolonial em que Tata Londirá se mostra como um grande narrador, apresentando suas narrativas não pelo texto escrito, mas através de elementos complexos que compõem as zuelas e os axós que trazem narrativas sobre os Nkises/Orixás.

Também é através das zuelas que Tata Londirá apresenta o candomblé. Mesmo sendo filiado ao candomblé denominado Angola, onde as falas ritualísticas são ligadas ao que denominamos ramo da língua bantu, em seus discos ouvimos zuelas de sua nação e, também, de outras denominações e troncos linguísticos ligados à tradição linguística iorubá e fon, como também saudações aos caboclos, que são evocados em português. Não nos deteremos em relatar com detalhes todos os álbuns ou programas de rádio dos quais participou. O efeitos dessas zuelas enquanto narrativas divulgadoras das “macumbas” perseguidas e consideradas como baixo espiritismo, reforçando o racismo estrutural tão bem engendrado nesse pós-abolição, é o que nos coloca no xirê/roda em diálogo com esse narrador que utiliza os mais diversos caminhos para desmitificar as práticas religiosas afrodiaspóricas.

A toada de abertura do texto faz parte de um álbum onde ouvimos Joãozinho da Goméia cantar para Nkisis, Orixás, Voduns, Caboclos e antes de cada toada anuncia a que o canto se refere, com voz pausada para só depois azuelar/cantar.

Periferia, v. 12, n. 3, p. 39-52, set./dez. 2020 

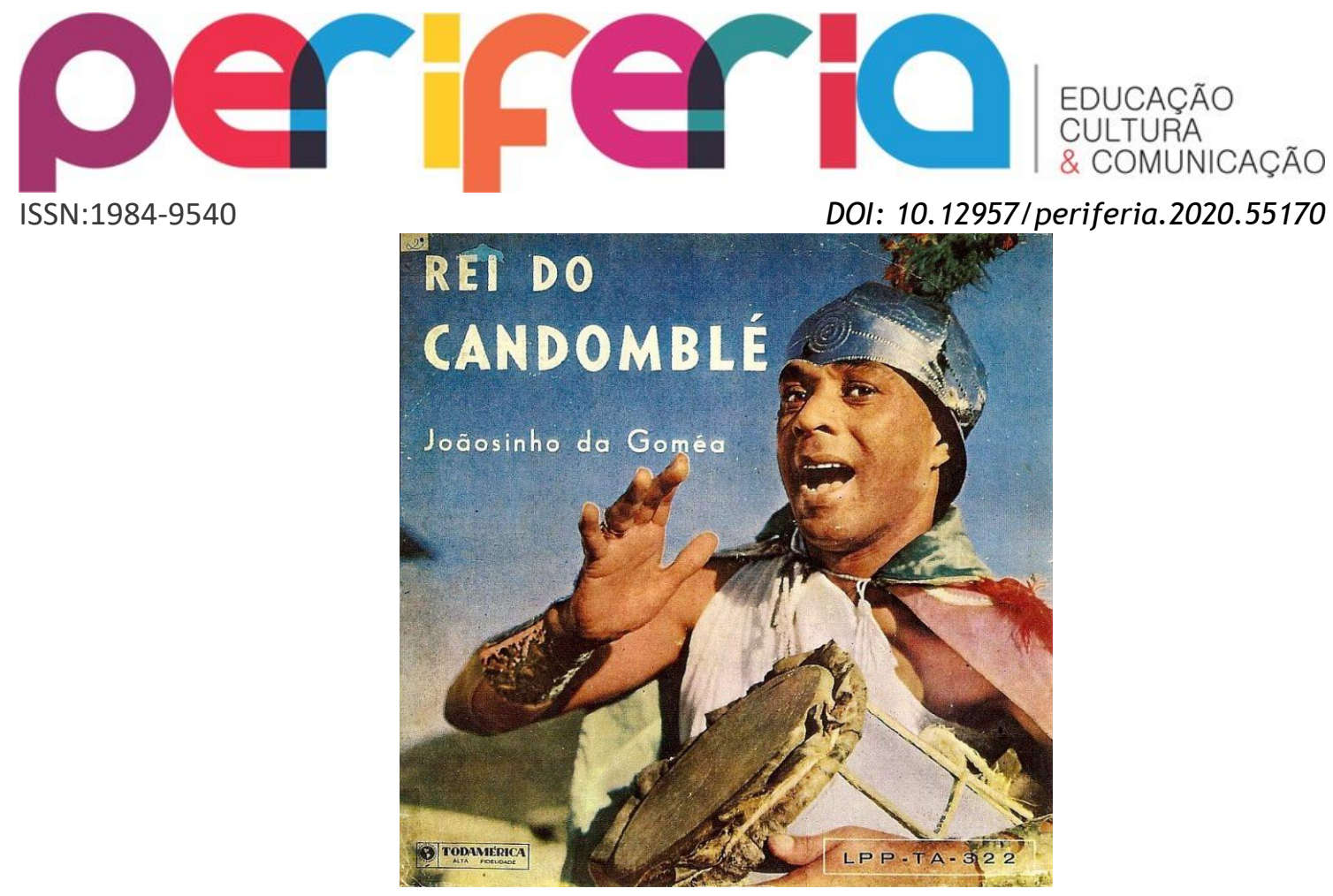

Capa do álbum de toadas "Rei do Candomblé”

Fonte: imagem de domínio público

Assim, nosso movimento neste ensaio procura destacar a força de narrador de Tata Londirá sobre os candomblés, por transpor para fora dos muros dos terreiros tais narrativas em toda sua estética, sonoridade, visualidade e encantamento. Pretendemos discutir os modos de produção dessas narrativas e as relações que podem ser estabelecidas entre encantamento e a produção de outros modos de escrita e leitura, configurando-se em uma narrativa decolonial.

\section{Narrativas decoloniais: além da divisão oralidade/escrita}

Dizer outros modos de escrita e leitura em narrativas decolonais nos faz propor uma discussão que provoque um deslocamento da dicotomia colonial posta entre sociedades orais e sociedades letradas, entre oralidade-escrita, a qual colocou uma centralidade da noção de escrita apenas atrelada ao verbal. Tal divisão acabou relegando tais práticas apenas ao âmbito da oralidade como forma de oposição e ausência de escrita, provocando uma redução da complexidade que envolve esses sistemas simbólicos. 


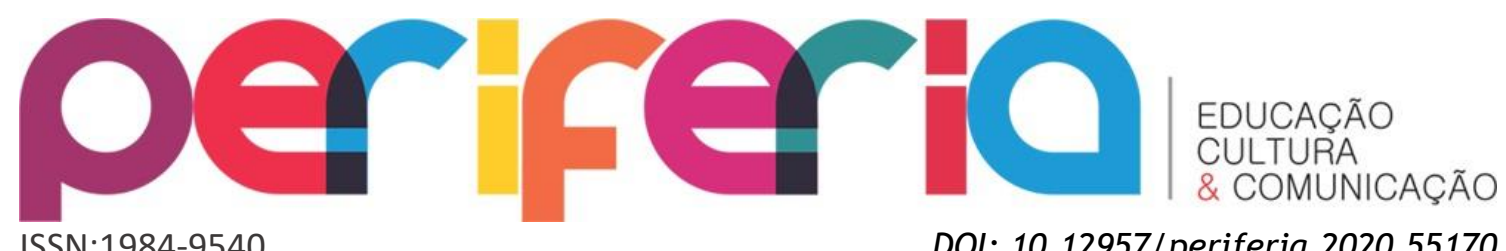

ISSN:1984-9540

DOI: $10.12957 /$ periferia. 2020.55170

Os processos de colonialidade do saber, como aponta Lander (2005), foram construídos a partir de sistemas de divisão binários, de oposição. Os modos de produção dessas ordens de saberes se deram a partir de divisões, separações essas desenvolvidas no Ocidente. Primeiro religiosa, na separação entre Deus, homem e natureza, em que o homem assumiria uma centralidade no controle da natureza e depois na divisão entre mente e corpo, razão e mundo. O mundo e o corpo ficaram vazios de significado relegando uma centralidade radical para a mente/razão. Assim, o mundo a partir dessas divisões passa a ser visto como um mecanismo desespiritualizado, que pode ser captado pelos conceitos e representações construídas pela razão, gerando uma forma de conhecimento descorporificado e descontextualizado. Assim, a partir da articulação pelo contraste, a conformação colonial do mundo propôs uma divisão entre ocidente ou europeu (signo do moderno e avançado) e os "outros" (restante dos outros povos e culturas do planeta).

Particularmente nos estudos em torno da escrita na década de 70 (Goody,1977; Goody \& Watt, 1977), esses procuraram estabelecer divisões entre sociedades orais e letradas, tomando como referência a centralidade da escrita nas sociedades letradas e procurando identificar vantagens de ordem cognitiva e social na aquisição de um sistema escrito. Nesse movimento há uma divisão que coloca do outro lado da dicotomia o que está na ausência, ou seja, apenas na "oralidade".

Nos trabalhos de Finnegan (1970, 2008), em seus estudos sobre literatura oral na África, é apresentada uma crítica aos estudos antropológicos que, a partir de uma ótica grafocêntrica, apenas identificaram a ausência da escrita em tais grupos, reduzindo suas práticas a uma pretensa "oralidade". Finnegan pontua que há um conjunto complexo de produção de sentidos não representados nem pela escrita nem somente calcados na oralidade. Ou seja, a produção de narrativas nessas práticas culturais apresenta-se de forma não segmentada entre fala (linguagem verbal), visualidade e corpo, pois fazem parte desse complexo os gestos, os ritmos, as emoções e o uso de sentidos como o tato, o olfato, a audição e a visão. Assim, as práticas narrativas se

Periferia, v. 12, n. 3, p. 39-52, set./dez. 2020 


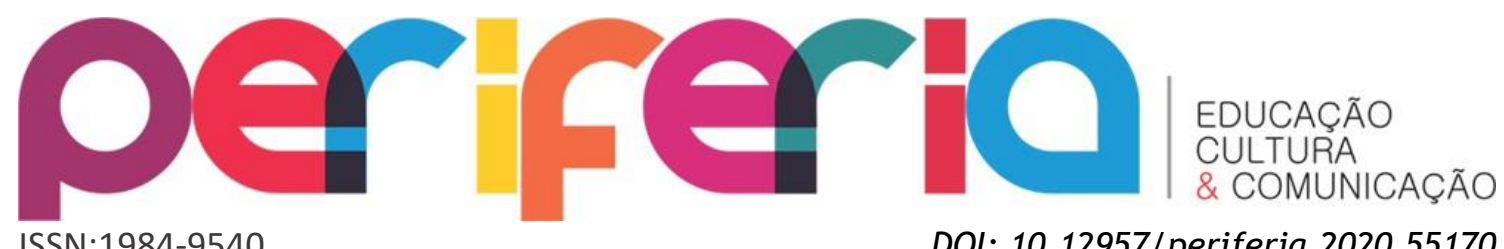

ISSN:1984-9540

DOI: $10.12957 /$ periferia. 2020.55170

realizam em formas complexas que envolvem diversos processos que se caracterizam de forma sinestésica.

Quando adentramos o texto de Hampate Bâ, "A tradição viva”, ele nos dá outra referência para pensar tanto sobre a 'fala' como a 'palavra'. É possível entender que as narrativas estabelecem vínculos com diversas formas de falar na medida que mantêm o caráter sagrado e sua vinculação divina às forças que compõem os efeitos dos atos de narrar. Hampate Bâ, ao abordar a questão da Palavra/Kuma na tradição bambara do Komo, afirma que ela funciona como um agente mágico, "é uma força fundamental que emana do próprio Ser Supremo, Maa Ngala" (Bâ, 2011, p. 170), a fala por sua vez concretiza a emanação da vibração dessas forças:

Maa Ngala, como se ensina, depositou em Maa as três potencialidades do poder, do querer e do saber, contidas nos vinte e um elementos dos quais ele foi composto. Mas todas essas forças, das quais é herdeiro, permanecem silenciadas dentro dele. Ficam em repouso até o instante em que a fala venha colocá-las em movimento. A fala é, portanto, considerada como a materialização, ou a exteriorização, das vibrações de força. (p. 172)

Indo além, pode-se dizer de que a fala provoca sentidos que extrapolam a apreensão verbal, "Quando Maa Ngala fala, pode-se ver, cheirar, saborear e tocar a sua fala”. Trata-se de uma percepção total, no qual o ser se envolve na totalidade.” (Bâ, 2011, p. 172). Encontramos nessa afirmação, elementos que nos fazem pensar sobre um tipo de composição de narrativas que entrelaçam o verbal a processos sinestésicos que vão gerar sentidos, percepções, formas de estar no mundo e de se relacionar com o sagrado e fazer vibrar suas forças, as quais vão compor processos que poderíamos pensar como encantamentos que se realizam a partir dessas enunciações. Encantamentos esses que adquirem movimento pela fala, a qual não ocorre de forma desvinculada de todos outros elementos sinestésicos acessados pelo corpo. Esses elementos vão compor a construção das narrativas que são produzidas nas práticas, as quais podemos pensar de modo particular no candomblé de Joãozinho da Goméia, bem como nas 


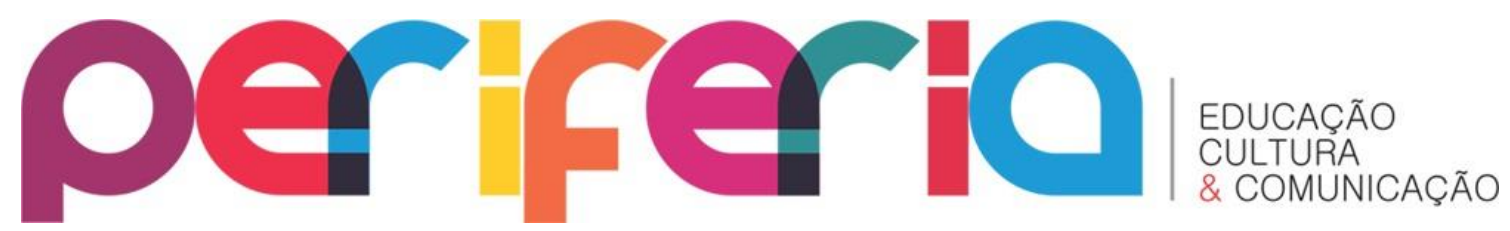

ISSN:1984-9540

DOI: $10.12957 /$ periferia.2020.55170

reverberações que são produzidas por ele ao ocupar outros lugares para compor suas narrativas.

\section{Modos de narrar e encantar}

O saber é uma luz que existe no homem. É a herança de tudo aquilo que nossos ancestrais puderam conhecer e que se encontra latente em tudo o que nos transmitiram, assim como o baobá já existe em potencial em sua semente. (BÂ, p.175-176, 2013)

No candomblé, a aprendizagem dos ritos e suas narrativas se dá a partir de uma série de elementos que envolvem aromas, visualidades, ritmos, movimentos e sensações. Desse modo, a apresentação dos axós/vestimentas dos Nkisis/Orixás, bem como dos participantes do culto, está sempre marcada pela beleza dos tecidos, pelos detalhes, pelos adereços, pelos bordados e pelos objetos. Apresentar uma narrativa é dar conta de cada detalhe que vai compor o visual desses axós com a finalidade tanto de produzir encantamentos, como produzir sentidos a partir de leituras que os participantes do culto vão poder fazer, de acordo com o seu tempo de vivência e aprendizagem das práticas que circulam no terreiro. Os tipos de tecidos utilizados, os acabamentos, compõem o corpo/texto (FERREIRA e MENDES, 2019), pois é a partir deles que é identificado o tempo de iniciado, se está pronto para festa ou trabalho, reverenciando qual Nkisi/Orixá dentre tantas outras leituras possíveis:

O corpo/texto resguardado, corpo/texto templo ritualístico, corpo texto que escuta narrativas/saberes através das histórias dos orixás (ítàn) e com cada uma delas, vai reconstruindo suas próprias narrativas, escritas (ou não), sua epistemologia própria.

Nossos discursos são impregnados de ancestralidade e conhecimentos - comidas, folhas, chás, adura (reza), cantos, danças, cuidados com ará (corpo), pois é corpo/texto lido dentro desses espaçostempos com muito cuidado e atenção, mas ignorado, vilipendiado, silenciado e invisibilizado para além dos muros do terreiro. (FERREIRA e MENDES, p.159, 2019)

Periferia, v. 12, n. 3, p. 39-52, set./dez. 2020 


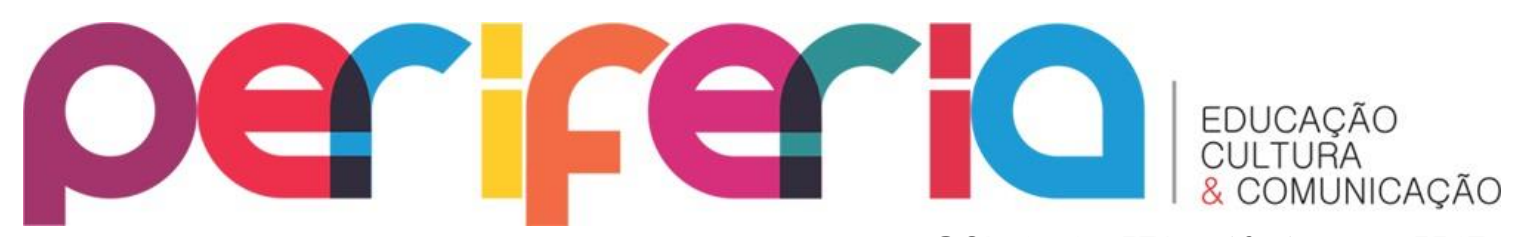

ISSN:1984-9540

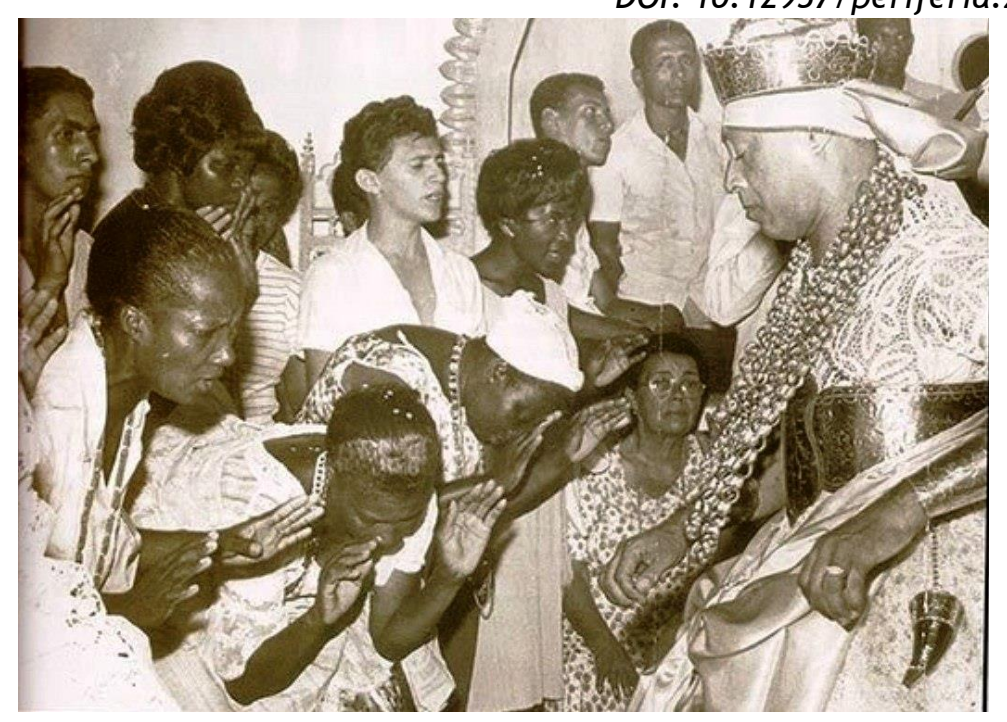

Matamba/lánsan / Joãozinho da Goméia em dança ritualística pública Fonte: imagem de domínio público

São esses conhecimentos ancestrais que Joãozinho da Goméia buscou desmistificar através das entrevistas, das fotos de axós usados nos cotidianos do terreiro e, também, dos axós de nkisis/orixás, da divulgação nas mídias da época de festas públicas do seu terreiro. Até mesmo quando as reportagens teciam duras críticas às atividades do terreiro, ao citar em tom de reprovação celebridades e políticos presentes, essas aguçavam a curiosidade, a perplexidade de alguns, mas principalmente, divulgavam suas atividades religiosas.

Outros detalhes que também constroem essas narrativas se mostram nas formas de zuelar, compostas pelos ritmos, entonações e pelas formas de soar os tambores. Cada um desses ritmos e entonações estão ligados a gestos, danças, aos ornamentos de mãos e aos axós que compõem esses textosbailados, resgatando memórias ancestrais que lemos nos espaços religiosos diaspóricos. Caçadas, disputas, seduções, banquetes fazem parte dessas narrativas, que foram tão bem apresentadas e utilizadas por Tata Londirá em espaços para além dos religiosos.

Assim, são alguns desses elementos que gostaríamos de destacar nas formas como Tata Londirá construiu suas narrativas sobre o candomblé, em uma época povoada por narrativas que relegavam o culto ao campo do exótico 


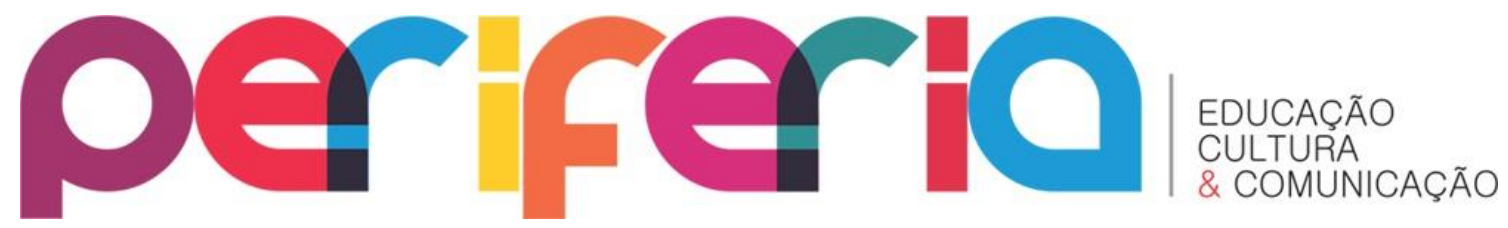

ISSN:1984-9540

DOI: $10.12957 /$ periferia. 2020.55170 e do misterioso. Mesmo sendo acusado em diversos momentos de estar folclorizando o candomblé por divulgar as danças, axós, zuelas sagradas em outros espaços, surgem análises que apontam suas estratégias como forma de desmistificar o candomblé (Gama, 2014). Elizabeth Gama nos chama atenção para pensar que:

O que para Bastide significava 'macumba para turista', Lody e Vagner Gonçalves descrevem como inteligência e sensibilidade. [...] Expor a religiosidade aos olhos de leigos, relacionando religião com cultura popular, foi uma das estratégias de reconhecimento e aceitação de João. Mas para isso ele teria que subverter as regras que sugeriam simplicidade no culto e, de fato, revolucionou algo que podemos notar nos dias atuais como uma herança de sua ousadia: a vestimenta dos orixás. (GAMA, p. 82, 2014)

Essa "quebra" consciente das tradições pode ser entendida como caminhos, estratégias de elaboração de suas narrativas lidas das mais variadas formas tanto por praticantes das religiosidades de matriz africana como por leigos e desconhecedores do candomblé.

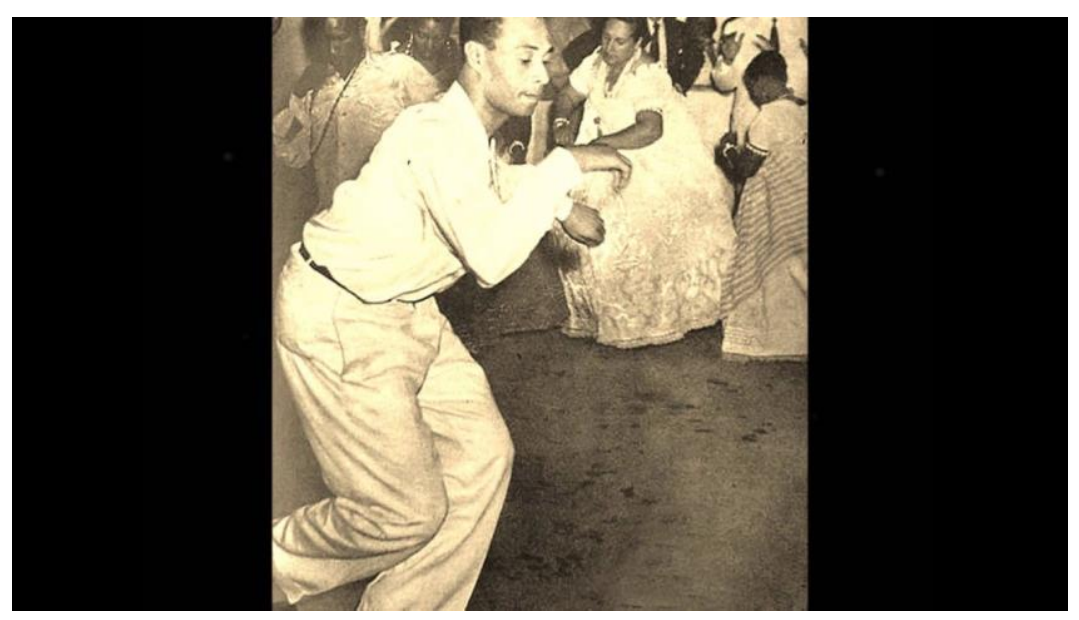

Joãozinho da Goméia

Fonte: imagem de domínio público

É importante perceber uma não compartimentação dos saberes apresentados por Joãozinho da Goméia. Por também ser dançarino e coreógrafo, sua experiência religiosa tem reflexo nas apresentações fora do terreiro; seu corpo/texto diaspórico, não se pautava nos binarismos e separações ocidentais convencionadas entre sagrado e profano, saberes 


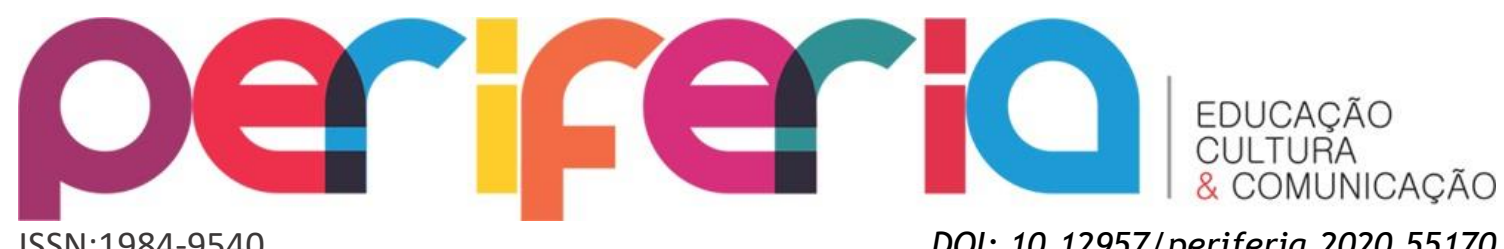

diaspóricos constitutivos de suas narrativas nos mais variados espaços, como

Bâ explica ao falar do que chama de grande escola oral:

(...) Tais homens eram capazes de abordar quase todos os campos do conhecimento da época, porque um 'conhecedor' nunca era um especialista no sentido moderno da palavra mas, mais precisamente, uma espécie de generalista. O conhecimento não era compartimentado. O mesmo ancião (no sentido africano da palavra, isto é, aquele que conhece, mesmo se nem todos os seus cabelos são brancos) podia ter conhecimentos profundos sobre religião ou história, como também ciências naturais ou humanas de todo tipo. Era um conhecimento mais ou menos global segundo a competência de cada um, uma espécie de 'ciência da vida', considerada aqui como uma unidade em que tudo é interligado, interdependente e interativo, em que o material e o espiritual nunca estão dissociados. E o ensinamento nunca era sistemático, mas deixado ao sabor das circunstâncias, segundo os momentos favoráveis ou a atenção do auditório. (BÂA, p. 175, 2013)

As imagens permitem leituras variadas de seu corpo/texto - do ponto de vista do leigo e da perspectiva de quem é praticante das religiosidades diaspóricas:

- Se está dançando para o nkisi/orixá.

- Se está dançando virado/incorporado com nkisi/orixá.

- Se virado/incorporado, é uma iabá/muatu/mulher ou oboró/diala/homem etc.

- Como os movimentos, gestos, vestimentas e adornos apresentam elementos narrativos sobre o nkisi/orixá.

- Como tais narrativas provocam, afetam e encantam os leitores desses corpo/textos

São leituras que terão perspectivas diferentes para os leigos e para os praticantes das religiosidades diaspóricas. Uma leitura mais aprofundada requer saberes, conhecimentos que são aprendidos nos cotidianos dos terreiros. Entretanto, Joãozinho da Goméia se propunha a oferecer seu corpo/texto sem distinção, mas com a preocupação de se fazer respeitar e 


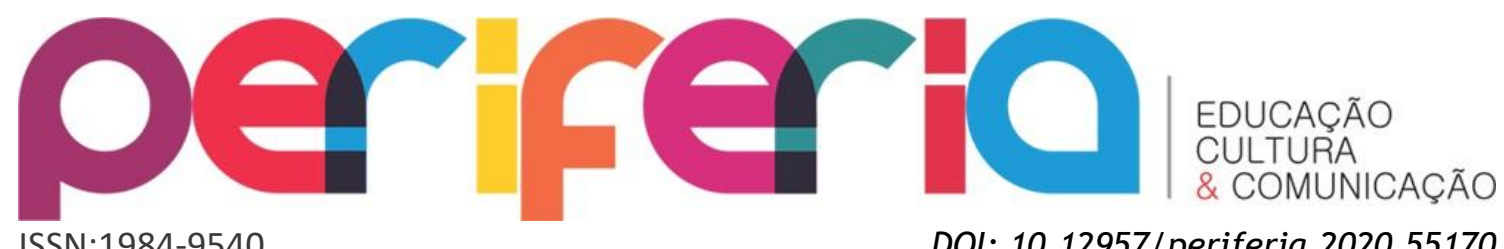

ISSN:1984-9540

DOI: $10.12957 /$ periferia. 2020.55170 aos seus, a partir da divulgação e apresentação do que sempre foi escondido e considerado como vergonhoso pela ordem vigente. Ele buscou minimizar perseguições e apoiar o estabelecimento do povo de candomblé próximo a ele. Atuou nas rasuras para divulgar as narrativas diaspóricas, ameríndias, sertanejas que o compunham, Como um estrategista, tomou espaços sem esconder quem era, sem se fragmentar - pai de santo, artista, homossexual conquistou espaçotempo, um reinado que prevalece até os dias atuais com seus corpo/textos, agora ancestral, sempre reverenciado por quem veio depois do seu legado de luta pelas práticas religiosas diaspóricas.

\section{Referências}

JÚNIOR, Assis. Dicionário Kimbundu-Português. Linguístico, Botânico, Histórico e Corográfico. Luanda: Argente Santos, sd.

BÂ, A. H. Amkoullel, o menino fula. São Paulo, Palas Athena, 2013.

BÂ, A. H. A tradição viva. In: KI-ZERBO, Joseph. Metodologia e pré-história da África. São Paulo, Cortez, 2011.

CAMPOS, M.D. SULear vs NORTEar: representações e apropriações do espaço entre emoção, empiria e ideologia. Documenta, VI, $N^{\circ}$ 8, Programa de Mestrado e Doutorado em Psicossociologia de Comunidades e Ecologia Social \&(EICOS)/Cátedra UNESCO de Desenvolvimento durável/UFRJ, Rio de Janeiro, 1999.

FERREIRA, M.S. MENDES, J.R. Saberes diaspóricos: SULear olhares, trançar sentidos. In: Revista Interdisciplinar SULear. Ano 2, №2, Setembro - Edição Especial Dossiê SULear, 2019.

FINNEGAN, R. O que vem primeiro: o texto, a música ou a performance? In: MATOS, Cláudia N.; TRAVASSOS, Elisabeth; MEDEIROS, Fernanda T. (orgs.). Palavra cantada. Rio de Janeiro: Letras, p. 15-43, 2008

FINNEGAN, R. Oral literature in Africa. Oxford: Clarendon Press, 1970.

GAMA, E. C. Mulato, Homossexual e macumbeiro: que rei é este? Trajetória de Joãozinho da Goméia (1914-1971). Duque de Caxias, APPH-CLIO, 2014. Série Recôncavo da Guanabara, volume 2.

GOODY, J. The Domestication of the Savage Mind, Cambridge Universiy Press, 1977.

Periferia, v. 12, n. 3, p. 39-52, set./dez. 2020 


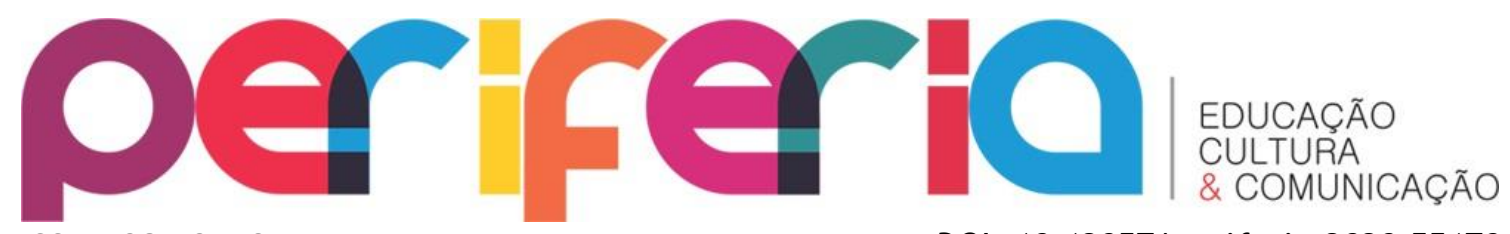

ISSN:1984-9540

DOI: $10.12957 /$ periferia. 2020.55170

GOOD, J. \& WATT. The consequences of Literacy, in Language and Social Context, Giglioli, P.P. (ed.), Penguin Education, 1977.

LANDER, E. Ciências sociais: saberes coloniais e eurocêntricos. In: LANDER, Edgardo (org). A colonialidade do saber: eurocentrismo e ciências sociais. Perspectivas latinoamericanas. Colección Sur Sur, CLACSO, Ciudad Autónoma de Buenos Aires, Argentina. Setembro, 2005.

MENDES, A. Vestidos de realeza: contribuições centro-africanas no candomblé de Joãozinho da Goméia, 1937-1967, dissertação de Mestrado, IFCH/Unicamp, 2012.

MENDES, A. Vestidos de realeza: fios e nós centro-africanos no candomblé de Joãozinho da Goméia. Duque de Caxias: APPH-CLIO, 2014. Série Recôncavo da Guanabara, v. 1, 2014.

Canal Youtube:

https: / / www.youtube.com/watch?v=WeJE9fxJBIY\&list=PLa3FSWWebyPOUfH4 7IGMW3WPWD6MR6Reu\&index $=8$ 